\title{
Enhancing the catalytic activity of a novel GH5 cellulase GtCel5 from Gloeophyllum trabeum CBS 900.73 by site-directed mutagenesis on loop 6
}

Fei Zheng ${ }^{1,2}$, Tao Tu' ${ }^{1}$, Xiaoyu Wang ${ }^{2}$, Yuan Wang ${ }^{1}$, Rui Ma ${ }^{1}$, Xiaoyun $\mathrm{Su}^{1}$, Xiangming Xie ${ }^{2}$, Bin Yao ${ }^{1 *}$ and Huiying Luo ${ }^{1 *}$

\begin{abstract}
Background: Cellulases of glycosyl hydrolase $(\mathrm{GH})$ family 5 share a $(\beta / \mathrm{a})_{8}$ TIM-barrel fold structure with eight $\beta a$ loops surrounding the catalytic pocket. These loops exposed on the surface play a vital role in protein functions, primarily due to the interactions of some key amino acids with solvent and ligand molecules. It has been reported that motions of these loops facilitate substrate access and product release, and loops 6 and 7 located at the substrate entrance of the binding pocket promote proton transfer reaction at the catalytic site motions. However, the role of these flexible loops in catalysis of GH5 cellulase remains to be explored.

Results: In the present study, an acidic, mesophilic GH5 cellulase (with optimal activity at pH 4.0 and $70{ }^{\circ} \mathrm{C}$ ), GtCel5, was identified in Gloeophyllum trabeum CBS 900.73. The specific activities of GtCel5 toward CMC-Na, barley $\beta$-glucan, and lichenan were $1117 \pm 43,6257 \pm 26$ and $5318 \pm 54 \mathrm{U} / \mathrm{mg}$, respectively. Multiple sequence alignment indicates that one amino acid residue at position 233 on the loop 6 shows semi-conservativeness and might contribute to the great catalytic performance. Saturation mutagenesis at position 233 was then conducted to reveal the vital roles of this position in enzyme properties. In comparison to the wild type, variants N233A and N233G showed decreased optimal temperature $\left(-10^{\circ} \mathrm{C}\right)$ but increased activities (27 and $\left.70 \%\right)$ and catalytic efficiencies $\left(k_{\text {cat }} / K_{m} ; 45\right.$ and 52\%), respectively. The similar roles of position 233 in catalytic performance were also verified in the other two GH5 homologs, TeEgI5A and PoCel5, by reverse mutation. Further molecular dynamics simulations suggested that the substitution of asparagine with alanine or glycine may introduce more hydrogen bonds, increase the flexibility of loop 6, enhance the interactions between enzyme and substrate, and thus improve the substrate affinity and catalytic efficiency.

Conclusion: This study proposed a novel cellulase with potentials for industrial application. A specific position was identified to play key roles in cellulase-substrate interactions and enzyme catalysis. It is of great importance for understanding the binding mechanism of $\mathrm{GH} 5$ cellulases, and provides an effective strategy to improve the catalytic performance of cellulases.
\end{abstract}

Keywords: GH5 cellulase, Saturation mutation, Catalytic activity, Loop region

\footnotetext{
*Correspondence: binyao@caas.cn; luohuiying@caas.cn

1 Key Laboratory for Feed Biotechnology of the Ministry of Agriculture,

Feed Research Institute, Chinese Academy of Agricultural Sciences, No. 12

South Zhongguancun Street, Haidian, Beijing 100081, People's Republic

of China

Full list of author information is available at the end of the article
} 


\section{Background}

Lignocellulose is composed of cellulose, hemicellulose, and lignin, and represents the most abundant renewable carbon source on earth [1]. The enzymatic hydrolysis of polysaccharides to monosaccharides is crucial from both viewpoints of cost and efficiency in the current practice of converting lignocellulosic biomass into biofuel. Complete hydrolysis of cellulose requires the cooperative actions of three types of cellulases: endoglucanase (EC 3.2.1.4) that randomly cleaves the internal $\beta-1,4$ glycosidic bonds; cellobiohydrolase (exoglucanase; EC 3.2.1.91) that processively acts on the chain termini to release cellobiose; and $\beta$-glucosidase (EC 3.2.1.21) that hydrolyzes cellobiose to glucose [2].

Based on the sequence and structure similarity of CAZymes (http://www.cazy.org), endoglucanases are grouped into 13 glycoside hydrolase $(\mathrm{GH})$ families, including GH5-9, 12, 44, 45, 48, 51, 74, 124, and 131 [3]. Of these, GH5 is the largest and the most functionally diverse group, and those from fungi are mainly confined into subfamily GH5_5 with endo- $\beta$-1,4-glucanase activity [4]. So far, six eukaryotic GH5 endoglucanases from Piromyces rhizinflata (PrEglA) [5], Thermoascus aurantiacus (TaCel5A) [6], Hypocrea jecorina (Trichoderma reesei) (TrCel5A) [7], Ganoderma lucidum (GlCel5A) [8], Aspergillus niger (AnCel5A) [9], and Penicillium verruculosum (PDB No. 5I6S) have been resolved. The typical catalytic domain of a GH5 cellulase has a canonical $(\beta / \alpha)_{8}$ TIMbarrel fold, in which the eight parallel $\beta$-strands and eight $\alpha$-helices are connected by seven $\beta \alpha$ or $\alpha \beta$ loops [10].

The loops that connect secondary structures are frequently located on the protein surface and are critical for substrate specificity and catalytic activity. For example, the mutation T113R of polygalacturonase PG8fn increased the plasticity of T3 loop and caused an improvement of the catalytic efficiency by $\sim 2.4$-fold [11]; modifying the loop conformations of two GH6 cellobiohydrolases facilitated the cellulose chain gliding and allowed more occasional endo-cleavages [12, 13]; and deletion of an exo-loop of a bacterial cellobiohydrolase altered its endolytic activity [14]. A few studies also reported the effects of loops on cellulases. For the cellulase Cel12A from Thermotoga maritima, a Tyr-to-Gly mutation on a unique loop related to substrate binding led to an increased specific activity by 1.7 -fold [15]. The protonation state of the catalytic glutamates of Cel5B from Clostridium thermocellum, with or without substrate, is largely governed by the conformational changes of $\beta_{3} \alpha_{3}$ loop [16]. When replacing the Phe267 with Ala of cellulase GtCel5E from Clostridium thermocellum, its hydrophobic interactions with two other residues were broken, the flexible loop was relocated, and the variant displayed an increased $k_{\text {cat }}$ value by fourfold [17]. These previous studies altogether reveal the importance of loop structures in enzyme catalysis.

Protein engineering is a prevalent method with numerous successes for enzyme improvements [18, 19]. Sitedirected mutagenesis based on rational design has been widely used to identify the roles of a specific amino acid residue. In the present study, a novel cellulase of GH5 from Gloeophyllum trabeum CBS 900.73, designated GtCel5, was produced in Pichia pastoris GS115. GtCel5 with great catalytic performance had asparagine at position 233 of loop 6 ( $\beta \alpha$ loop), the same as the structureresolved homologs $\mathrm{GlCel} 5 \mathrm{~A}(72 \%, 5 \mathrm{D} 8 \mathrm{~W})$ and $\operatorname{Tr} \mathrm{Cel} 5 \mathrm{~A}$ $(69 \%, 3 \mathrm{QR} 3)$ of GH5_5 [3, 4]. In contrast, some other GH5 cellulases have glycine at this position. In order to gain insights into the functional role of loop 6 in GH5 cellulases, we created saturation mutants of GtCel5 at position 233 by site-directed mutagenesis. The results were then verified by reverse mutation on two GH5 homologs. Biochemical and bioinformatics analyses indicated that residue 233 on loop 6 is critical for the substrate binding and catalytic efficiency.

\section{Methods \\ Strains and plasmids}

The donor strain G. trabeum CBS 900.73 from the CBSKNAW Fungal Biodiversity Center (Utrecht, the Netherlands) was grown at $30{ }^{\circ} \mathrm{C}$ for 3 days in a lignocellulose medium containing (w/v) $5 \mathrm{~g} / \mathrm{L} \mathrm{NaCl}, 5 \mathrm{~g} / \mathrm{L}\left(\mathrm{NH}_{4}\right)_{2} \mathrm{SO}_{4}$, $1 \mathrm{~g} / \mathrm{L} \quad \mathrm{KH}_{2} \mathrm{PO}_{4}, 0.5 \mathrm{~g} / \mathrm{L} \quad \mathrm{MgSO}_{4} \cdot 7 \mathrm{H}_{2} \mathrm{O}, 0.2 \mathrm{~g} / \mathrm{L} \mathrm{CaCl}_{2}$, $0.01 \mathrm{~g} / \mathrm{L} \mathrm{FeSO}_{4} \cdot 7 \mathrm{H}_{2} \mathrm{O}, 15 \mathrm{~g} / \mathrm{L}$ corncob, $15 \mathrm{~g} / \mathrm{L}$ soybean meal, and $15 \mathrm{~g} / \mathrm{L}$ wheat bran. Plasmid pPIC9 harboring an ampicillin resistance gene was used for selection in Escherichia coli Trans I-T1 (TransGen, Beijing, China). Transformed E. coli was maintained on LB medium supplemented with $100 \mu \mathrm{g} / \mathrm{mL}$ ampicillin and grown at $37^{\circ} \mathrm{C}$. Cellulases $\mathrm{TeEgl5A}$ from Talaromyces emersonii [20] and PoCel5 from Prosthecium opalus (unpublished data) were selected for reverse mutation. Plasmids pPIC9-Teegl5A and pPIC9-Pocel5 containing the cDNA fragments of mature $T e E g 15 \mathrm{~A}$ and PoCel5-encoding sequences were used as the PCR templates. Plasmid DNA was isolated from E. coli using a Qiagen Miniprep Kit. P. pastoris GS115 (Invitrogen) was maintained on MD plates ( $2 \%$ glucose and $2 \%$ agarose) at $30{ }^{\circ} \mathrm{C}$.

\section{Gene cloning}

Fungal RNA was isolated and purified from $100 \mathrm{mg}$ of 3-day-old mycelia grown in the lignocellulose medium using the SV Total RNA Isolation System (Promega). cDNAs were synthesized in vitro using the ReverTra Ace-a-TM kit (TOYOBO, Osaka, Japan) with total RNA as the template. Amplification of the GtCel5 gene was carried out using the oligonucleotide primer 
set GtCel5-F and GtCel5-R (5'-CCGAATTCGCC GCGCTCTCTCCGAGAGTGACA-3', and 5' ${ }^{\prime}$-ACT GCGGCCGCTCATGCGTTGGCAATCGGAGCCAA GCA-3', with the EcoRI and NotI restriction sites underlined). The $50-\mu \mathrm{L}$ PCR contained $10 \mu \mathrm{g}$ of cDNA template, $5 \mu \mathrm{M}$ of each primer, $1 \mathrm{mM}$ of dNTPs, $5 \mu \mathrm{L}$ of $10 \times$ PCR buffer, and $1 \mu \mathrm{L}$ of Taq DNA polymerase (Fermentas; $2.5 \mathrm{U} / \mu \mathrm{L}$ ). The specific PCR products were digested with EcoRI and NotI to create sticky ends and ligated to the EcoRI-NotI-digested vector pPIC9 using T4 DNA ligase (New England Laboratory). The constructed recombinant plasmid pPIC9-Gtcel5 was then transformed into E. coli Trans I-T1 competent cells. Positive transformants were sequenced for verification.

\section{Sequence analysis}

The DNA and amino acid sequences were analyzed using the BLASTx and BLASTp programs (http://www. ncbi.nlm.nih.gov/BLAST/), respectively. The introns, exons, and transcription initiation sites were predicted using the GENSCAN Web Server (http://genes.mit. edu/GENSCAN.html). SignalP 3.0 was used to predict the signal peptide sequence (http://www.cbs.dtu.dk/ services/SignalP/). The potential $N$-glycosylation sites were predicted online (http://www.cbs.dtu.dk/servi ces/NetNGlyc/). Sequence assembly and estimation of the molecular mass and $p \mathrm{I}$ of the mature peptide were performed using the Vector NTI Suite 10.0 software (Invitrogen). MEGA 4.0 was used for inferring the phylogenetic relationship of GH5 cellulases [21].

\section{Selection of the mutation site and site-directed mutagenesis}

Loop 6 of $G t$ Cel 5 is in close proximity to the catalytic pocket and the component residues YLDSDN are capable of forming a unique hairpin structure (Fig. 1). Identification and multiple sequence alignment of 51 fungal cellulases of GH5 were conducted using the FASTA [22] and ClustalW [23] algorithms. Based on the structure and sequence analysis of loop 6 , a key residue probably related to GtCel5 functionality was identified, and selected for saturation mutagenesis. With recombinant plasmids pPIC9Gtcel5, pPIC9-Teegl5A, and pPIC9-Pocel5 as the templates, the mutants were first constructed by overlap PCR for preliminary screening. Reverse mutations of G216A and G216N of TeEg15A and G210A and G210N of PoCel5 were performed using the Fast Mutagenesis System Kit (TransGen) with 30 amplification cycles. The primer pairs used in this study are listed in Additional file 1: Table S1.

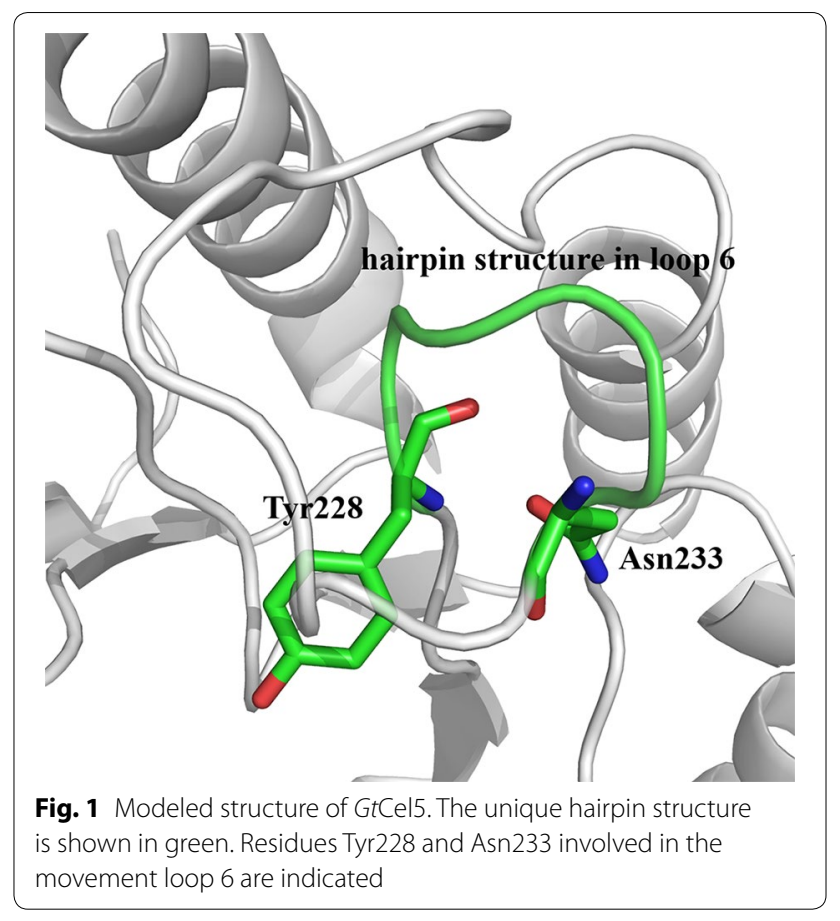

\section{Enzyme expression and purification}

Recombinant plasmids containing the gene fragments coding for the wild-type and mutant enzymes of GtCel5, $T e$ Egl5A, and PoCel5 were then linearized with BglII for transformation into P. pastoris GS115. The positive transformants were screened on MD plates. Ninety-six positive transformants of each enzyme were selected to grow in $3 \mathrm{~mL} \mathrm{BMGY}$ at $30{ }^{\circ} \mathrm{C}$ for $48 \mathrm{~h}$, collected, and resuspended in $1 \mathrm{~mL}$ BMMY containing $0.5 \%$ methanol for 72 -h enzyme induction at $30{ }^{\circ} \mathrm{C}$. The culture supernatants of each transformant were collected by centrifugation at $12,000 \times g$ for $10 \mathrm{~min}$ at $4{ }^{\circ} \mathrm{C}$ and examined by activity assay. The transformants showing the highest cellulase activities were inoculated into $30 \mathrm{~mL}$ YPD and incubated at $30{ }^{\circ} \mathrm{C}, 200 \mathrm{rpm}$ for $48 \mathrm{~h}$, and transferred into $400 \mathrm{~mL}$ BMGY in 1-L Erlenmeyer flasks for $48-\mathrm{h}$ growth. Cells were then harvested by centrifugation at $4500 \times g$ for $5 \mathrm{~min}$ at $4{ }^{\circ} \mathrm{C}$ and resuspended in $200 \mathrm{~mL}$ of BMMY containing $0.5 \%(\mathrm{v} / \mathrm{v})$ methanol for $48 \mathrm{~h}$ at $30{ }^{\circ} \mathrm{C}$ for induction.

Cell-free cultures were collected by centrifugation at $12,000 \times g$ for $10 \mathrm{~min}$ at $4{ }^{\circ} \mathrm{C}$. Further purification was performed using the HiTrap Q HP anion exchange column (Amersham Biosciences, Uppsala, Sweden). Binding buffer was composed of $10 \mathrm{mM}$ sodium phosphate ( $\mathrm{pH}$ 7.5). Elution was performed using a linear gradient of $0-1 \mathrm{M}$ sodium chloride in the same buffer. The purities of the enzymes were checked with $12 \%$ SDS-polyacrylamide gel electrophoresis (PAGE) and Coomassie 
blue staining. Endo- $\beta$ - $N$-acetylglucosaminidase $\mathrm{H}$ (Endo H) from New England Biolabs was used to remove $N$-glycosylation according to the manufacturer's instructions. Purified proteins were quantified using the Bradford protein assay kit (Bio-Rad) and then used for enzyme characterization.

\section{Cellulase activity assay}

CMC-Na (medium viscosity) from Sigma-Aldrich at a concentration of $10 \mathrm{mg} / \mathrm{mL}$ was used as the substrate. The assay mixtures contained $900 \mu \mathrm{L}$ of substrate solution in $100 \mathrm{mM}$ Mcllvaine buffer (optimal pH) and $100 \mu \mathrm{L}$ of appropriately diluted enzyme. The reaction mixtures were incubated at optimal temperature for $10 \mathrm{~min}$, followed by the addition of $1.5 \mathrm{~mL} \mathrm{3,5-dinitrosalicylic} \mathrm{acid}$ (DNS) and incubation in a $100{ }^{\circ} \mathrm{C}$ water-bath for $5 \mathrm{~min}$ [24]. The amounts of reducing sugar released were measured at $540 \mathrm{~nm}$, and one unit of the cellulase activity was defined as the amount of enzyme that released $1 \mu \mathrm{mol}$ of reducing sugar per minute.

\section{Biochemical characterization}

CMC-Na was used as the substrate for enzyme characterization. The buffers used were $100 \mathrm{mM} \mathrm{KCl}-\mathrm{HCl}(\mathrm{pH}$ 1.0-3.0), $100 \mathrm{mM}$ citric acid- $\mathrm{Na}_{2} \mathrm{HPO}_{4}(\mathrm{pH} 2.2-7.0)$, $100 \mathrm{mM}$ Tris- $\mathrm{HCl}$ (pH 8.0-9.0), and $100 \mathrm{mM}$ glycine$\mathrm{NaOH}$ ( $\mathrm{pH}$ 9.0-12.0). The $\mathrm{pH}$-activity profile of each enzyme was determined at optimal temperature in buffers of $\mathrm{pH}$ 2.2-8.0. The temperature-activity profile of each enzyme was determined at optimal $\mathrm{pH}$ over the temperature range from 40 to $90{ }^{\circ} \mathrm{C}$. For $\mathrm{pH}$ stability, each enzyme was preincubated at $37^{\circ} \mathrm{C}$ for $1 \mathrm{~h}$ in buffers of different $\mathrm{pH}(1.0-12.0)$ and subjected to the residual activity assay under standard conditions as described above. For thermostability assay, each enzyme (approximately $100 \mu \mathrm{g} / \mathrm{mL}$ ) was preincubated at 60 or $70{ }^{\circ} \mathrm{C}$ for 0-60 min, and aliquots of $100 \mu \mathrm{L}$ were withdrawn at specific time points for residual activity assay.

\section{Substrate specificity}

Polysaccharides from Sigma-Aldrich and Megazymes (Wicklow, Ireland) containing different glycosidic linkages, including $\mathrm{CMC}-\mathrm{Na}$, barley $\beta$-glucan, lichenan, laminarin, konjac glucomannan, Avicel, locust bean gum, xylan, and filter paper, were used to test the substrate specificity of GtCel5 under standard conditions. The specific activities of $G t C e l 5$ variants toward barley $\beta$-glucan and $\mathrm{CMC}-\mathrm{Na}$ were also determined and compared to that of the wild type.

\section{Kinetic assays}

Kinetic parameters of the enzymes were derived from the reactions under optimal conditions with $0.125-10 \mathrm{mg} /$
$\mathrm{mL} \mathrm{CMC}-\mathrm{Na}$ as the substrate. Initial velocities were determined by measuring the production rates of reducing sugar with the DNS method. The kinetic parameters (apparent $K_{\mathrm{m}}$ and $k_{\text {cat }}$ ) were calculated using the GraphPad Prism 6.0 (http://www.graphpad.com/scientific -software/prism/) and the nonlinear regression algorithm embedded in the enzyme kinetics module. The catalytic efficiency $\left(k_{\text {cat }} / K_{\mathrm{m}}\right)$ of each enzyme was then calculated.

\section{Bioinformatic analyses}

Discovery Studio 2017 software was used for automated comparative modeling of $G t \mathrm{Cel} 5$ and its variants with $\operatorname{Tr}$ Cel5A (3QR3, 69\% identity) as the template. To explore the possible roles of site-directed mutagenesis at position 233, molecular dynamic (MD) simulation was conducted to compare the dynamic properties of monomeric GtCel 5 and its variants N233A, N233D, and N233G. All of the MD simulations were carried out using the Amber 14 package at a temperature of $323 \mathrm{~K}$ for $20 \mathrm{~ns}$. Force field ff99SB with the TIP3P water model was used to describe the systems [25-27]. All protein atoms were at least 12 Ácc from the edge of the water box. The systems had net negative charges and were neutralized by addition of sodium ions with the Amber tool program [28]. Prior to the MD simulations, each system was carried out with 10,000 steps of steepest descent for energy minimizations. The trajectories of the first 5 ns were treated as equilibration periods, and the trajectories of the last $15 \mathrm{~ns}$ were used for data analyses. The root-mean-square deviation (RMSD) and root-mean-square fluctuation (RMSF) values of the $C_{\alpha}$ atoms calculated from the equilibrium state were plotted as a function of residue number.

To analyze the interactions between enzyme and substrate, cellotetraose (G4) was docked to GtCel5 and its variants N233A and N233G, respectively, using YASARA software (http://www.yasara.org). MD simulations of the enzyme-cellotetraose complex were then carried out at a temperature of $323 \mathrm{~K}$ for $20 \mathrm{~ns}$. The Amber force fields ff99SB and GLYCAM_06 [26, 29] were employed to model the cellulase and cellotetraose, respectively. Five thousand snapshots taken from the last 5-ns MD trajectories were used for molecular mechanics/Poisson Boltzmann and surface area continuum solvation (MM/PBSA) calculations. The binding free energy between ligand and protein was calculated by the Amber14. The $\Delta G$ value was determined according to the equation: $\Delta G=$ $G_{\text {complex }}-G_{\text {receptor }}-G_{\text {ligand }}$. The contributions of internal, electrostatic, and van der Waals' energy to $\Delta G$ were analyzed using the force field (http://ambermd.org/tutorials/ advanced/tutorial3/py_script/section2.htm) [30].

Hydrogen bond is one of the most important directional intermolecular interactions [31]. Putative hydrogen bonds were assigned based on two geometric criteria: the 
distance of less than $3.5 \AA$ and the angle larger than $120^{\circ}$ between the acceptor and the hydrogen donor. Visualization and figure preparation of the three dimensional molecules were performed using the PyMOL version 1.7.2.1 (Delano Scientific).

\section{Results}

\section{Cloning and sequence analysis of Gtcel5}

A GH5 cellulase-encoding gene, Gtcel5 (GenBank Accession No. XP_007867902), was identified in the genome of G. trabeum CBS 900.73. The Gtcel5 contains 1415 base pair that is composed of 7 exons and 6 introns. Deduced GtCel5 contained 359 amino acid residues including a putative $\mathrm{N}$-terminal signal peptide of 20 amino acids. The catalytic domain showed the highest amino acid sequence identity of $73 \%$ with the Cel 4 from Polyporus arcularius and the endo- $\beta-1,4$-glucanase from Sporotrichum thermophile, and $72 \%$ with the structure-resolved GlCel5A (5D8W) [8] and 69\% with the structureresolved $\operatorname{Tr}$ Cel5A (3QR3) [7]. As most fungal cellulases of GH5 (EC3.2.1.4) are classified into subfamily GH5_5 [4], GtCel5 is closely related to cellulases $5 \mathrm{D} 8 \mathrm{~W}$ and BAF75943 belonging to the same subfamily (see Additional file 1: Fig. S1). Homology modeling indicated that GtCel5 folds into a typical $(\beta / \alpha)_{8}$ structure and contains eight highly conserved residues of GH5 enzymes, including Arg67, His111, Asn154, Glu155, His226, Tyr228, Glu267, and Trp300 (numbering without the signal peptide sequence).

\section{Selection of the mutagenesis site in GtCel5}

Loop regions are proposed to play vital roles in the interactions between TIM-barrel enzymes and substrate [11, 13, 32, 33]. Structure and sequence analysis (Figs. 1, 2) indicated that the Tyr228 and Asn 233 of GtCel5 might be the key switch residues to control the movement of loop 6. The conformational plasticity of this hairpin structure might affect the catalytic performance of GtCel5. Tyr228 was highly conserved, while Asn233 showed variation. Therefore, we selected N233 for saturation mutagenesis to investigate the effects of the residue at position 233 on catalytic efficiency of GH5 cellulases.

\section{Production of GtCel5 and its mutants in P. pastoris}

GtCel5 and its 19 mutant enzymes were successfully expressed in P. pastoris GS115. One protein band of GtCel5 with the apparent molecular weight of approximately $40 \mathrm{kDa}$ was detected on the SDS-PAGE (Additional file 2: Fig. S2), which was higher than the calculated value $(35.7 \mathrm{kDa})$. After Endo $\mathrm{H}$ digestion, the $\mathrm{N}$-deglycosylated GtCel5 decreased to approximately $36 \mathrm{kDa}$. Mutant enzymes had similar apparent molecular weights, and showed a single band with expected molecular mass after Endo $\mathrm{H}$ treatment (data not shown).

\section{Comparison of the enzymatic properties between GtCel5 and its variants}

When using CMC-Na as the substrate, GtCel5A showed the highest activity at $\mathrm{pH} 4.0$ and remained more than $30 \%$ active at $\mathrm{pH}$ values between 2.2 and 6.0 (Fig. 3a). This $\mathrm{pH}$-activity profile is similar to those of most fungal cellulases. The variants except for N233V showed similar $\mathrm{pH}$ optima to the wild type, and the optimal $\mathrm{pH}$ of N233V shifted to pH 5.0 (Fig. 3a). As shown in Fig. 3b, GtCel5A had an optimal temperature of $70{ }^{\circ} \mathrm{C}$. All of the variants except for N233D were optimally active at 50 or $60{ }^{\circ} \mathrm{C}$, which was $10-20{ }^{\circ} \mathrm{C}$ lower than the wild type, while N233D had similar optimal temperature to the wild type. In comparison with the wild type, all variants showed decreased activities except for N233A, N233G, N233S, and N233D (Fig. 3a, b). The stabilities of GtCel5A and mutants N233A, N233G, and N233D were also compared. For $\mathrm{pH}$ stability, GtCel5 retained more than $65 \%$ of its initial activity after 60 -min incubation at $37^{\circ} \mathrm{C}$ over a wide $\mathrm{pH}$ range (3.0-12.0), while the variants $\mathrm{N} 233 \mathrm{D}$ and N233G retained stability over a wider $\mathrm{pH}$ range (over $70 \%$ activity after 1-h incubation at $\mathrm{pH} 2.0-12.0$ ) (Fig. 3c). The good stability under both acidic and alkaline conditions makes variants N233D and N233G more favorable for applications in the industries of bioethanol, detergents, and feed additives. GtCel5 and variants N233A, N233D, and N233G showed similar thermostability (Fig. 3d). The results suggested that the single mutation at position 233 had significant effects on some enzyme properties of GtCel5.

\section{Substrate specificities and kinetics of GtCel5 and its mutants}

Of the nine polysaccharide substrates tested, GtCel5 showed the highest activity on barley $\beta$-glucan $(6257 \pm 26 \mathrm{U} / \mathrm{mg})$ and lichenan $(5318 \pm 54 \mathrm{U} / \mathrm{mg})$, moderate on CMC-Na (1117 $\pm 43 \mathrm{U} / \mathrm{mg})$, low toward locust bean gum, and no detectable activity on Avicel, filter paper, xylan, and laminarin. These results indicated that GtCel5 had no activity on crystalline cellulose and $\beta-1,3$ glycosidic linkages. Using $\mathrm{CMC}-\mathrm{Na}$ as the substrate, GtCel5 had the $K_{\mathrm{m}}, V_{\text {max }}$, and $k_{\text {cat }}$ values of $4.5 \pm 0.3 \mathrm{mg} /$ $\mathrm{mL}, 1475 \pm 71 \mu \mathrm{mol} / \mathrm{min} / \mathrm{mg}$, and $878 \pm 44 / \mathrm{s}$, respectively, according to the Lineweaver-Burk plot.

CMC-Na was selected as the substrate to compare the specific activities and kinetic values of GtCel5 and its variants (Table 1). For the substitutions at position 233, the main outcome was a significant decrease in specific activity (1.4-138.6-fold) and $k_{\text {cat }}(0.7-66.5$-fold). A few of the variants also showed an increase of $K_{\mathrm{m}}$ (variants N233M, 


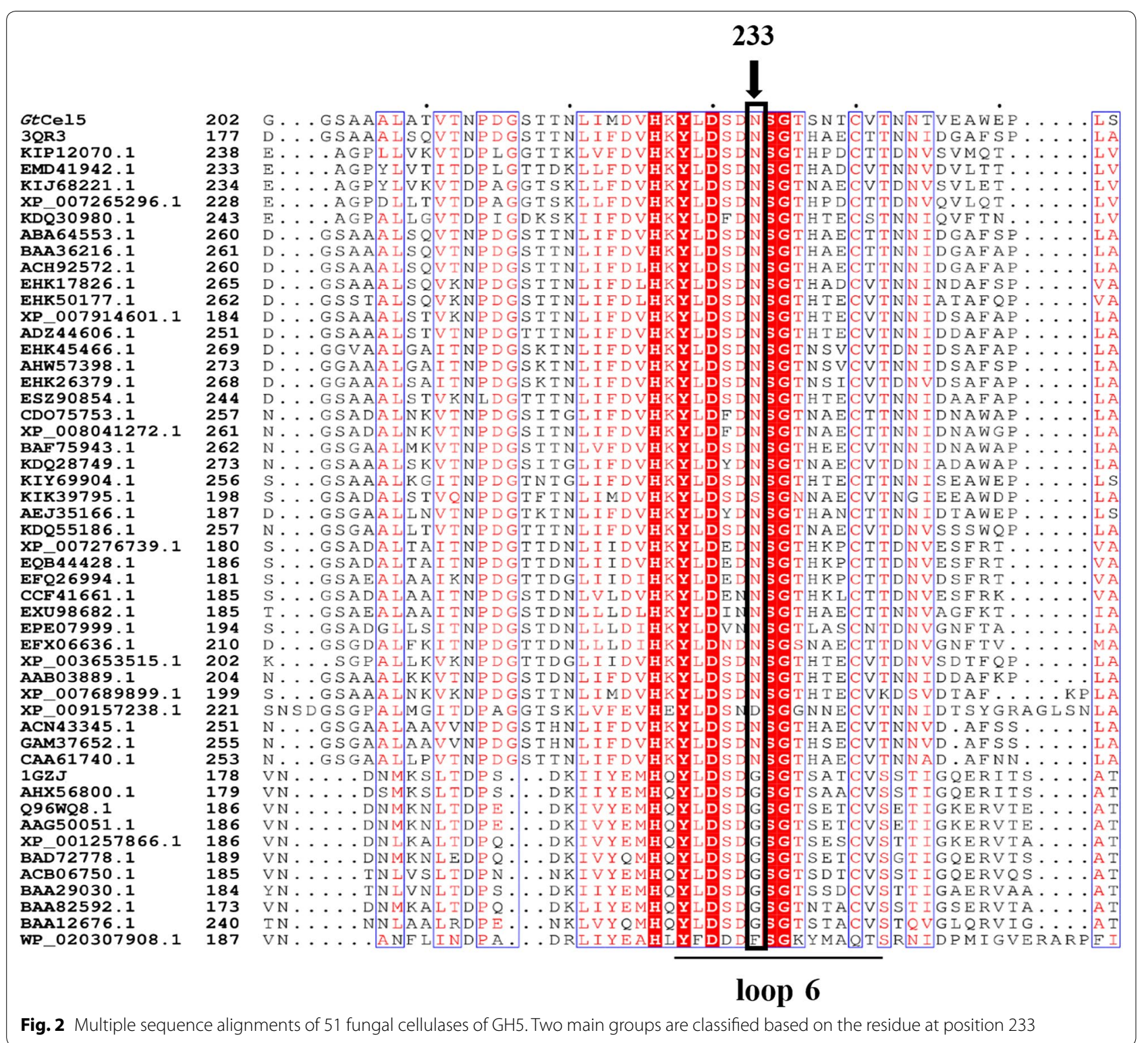

N233L, N233Y, N233W, N233K, N233V, and N233P). Interestingly, some of the variants gave an increased specific activity, $k_{\text {cat }}$, and $k_{\text {cat }} / K_{\mathrm{m}}$ (catalytic efficiency). These were N233A and N233G. These two variants also showed increased specific activities of 1.3- and 1.7-folds toward barley $\beta$-glucan in comparison to the wild type (Table 2 ). The results in combination indicated that glycine or alanine at position 233 contributed to the improved catalytic performance of $G t$ Cel5.

\section{Reverse mutations on TeEgl5A and PoCel5}

In order to validate the effect of position 233 on catalytic efficiency, reverse mutation was performed on another two GH5 cellulases: TeEgl5A [20] and PoCel5. The corresponding Gly216 of TeEgl5A and Gly210 of PoCel5 were substituted by asparagine or alanine, respectively, to generate four variants TeEgl5A_G216A, TeEgl5A_G216N, PoCel5_G210A, and PoCel5_G210N. All enzymes were successfully produced in P. pastoris GS115 and showed bands of theoretical molecular masses after Endo $\mathrm{H}$ treatment (Additional file 2: Fig. S3).

With CMC-Na as the substrate, TeEgl5A and its variants TeEgl5A_G216A and TeEgl5A_G216N were optimally active at $\mathrm{pH} 4.0$ and $90{ }^{\circ} \mathrm{C}$, while PoCel5 and its variants PoCel5_G210A and PoCel5_G210N showed optimal activities at pH 5.0 and $60{ }^{\circ} \mathrm{C}$ (Additional file 2: Fig. S4). These results indicated that the single specific mutation of glycine with asparagine or alanine has no 

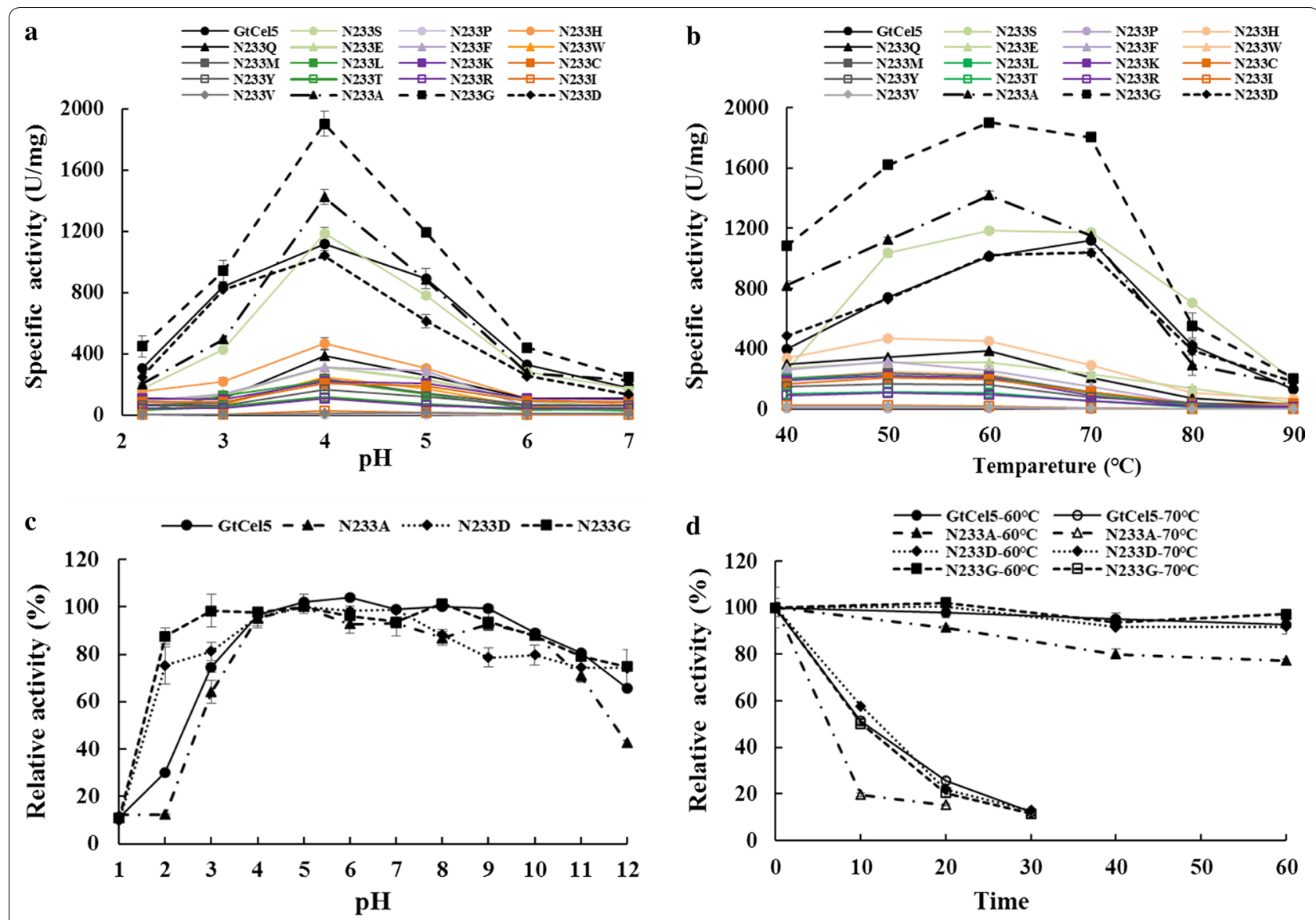

Fig. 3 Enzymatic properties of the wild-type GtCel5 and its variants. a pH-activity profiles tested at the optimal temperature of each enzyme with $10 \mathrm{mg} / \mathrm{mL}$ CMC-Na as the substrate in $100 \mathrm{mM}$ citric acid- $\mathrm{Na}_{2} \mathrm{HPO}_{4}$ buffer over the $\mathrm{pH}$ range of 2.2-7.0 for $10 \mathrm{~min}$. b Temperature-activity profiles tested at the optimal $\mathrm{pH}$ of each enzyme in the temperature range of $40-90^{\circ} \mathrm{C}$ for $10 \mathrm{~min}$. $\mathbf{c ~ p H}$-stability profiles determined by measuring the residual activity at optimal $\mathrm{pH}\left(100 \mathrm{mM}\right.$ citric acid- $\left.\mathrm{Na}_{2} \mathrm{HPO}_{4}\right)$ and temperature for $10 \mathrm{~min}$ after 1 -h incubation at pH $1.0-12.0$ and $37^{\circ} \mathrm{C}$ without substrate. $\mathbf{d}$ Temperature-stability profiles investigated by measuring the residual activity at optimal $\mathrm{pH}$ and temperature after incubation at different temperatures for various durations

Table 1 The kinetic values of GtCel5, TeEgI5A, PoCel5, and their mutants with CMC-Na as the substrate

\begin{tabular}{llcccc}
\hline Enzymes & $\begin{array}{l}\text { Specific activity } \\
(\mathbf{U} / \mathbf{m g})\end{array}$ & $\boldsymbol{K}_{\mathbf{m}}(\mathbf{m g} / \mathbf{m L})$ & $\boldsymbol{V}_{\mathbf{m a x}}(\boldsymbol{\mu \mathbf { m o l } / \mathbf { m i n } / \mathbf { m g } )}$ & $\boldsymbol{k}_{\text {cat }}(\mathbf{s})$ & $\boldsymbol{k}_{\text {cat }} / \boldsymbol{K}_{\mathbf{m}}(\mathbf{m L} / \mathbf{s} / \mathbf{m g})$ \\
\hline GtCel5 & $1117 \pm 43$ & $4.5 \pm 0.3$ & $1475 \pm 71$ & $878 \pm 44$ & $195 \pm 6$ \\
N233G & $1901 \pm 21$ & $3.6 \pm 0.4$ & $1802 \pm 96$ & $1072 \pm 63$ & $297 \pm 8$ \\
N233A & $1419 \pm 22$ & $3.7 \pm 0.3$ & $1742 \pm 96$ & $1036 \pm 57$ & $283 \pm 4$ \\
N233D & $1185 \pm 35$ & $4.4 \pm 0.7$ & $1511 \pm 98$ & $899 \pm 87$ & $202 \pm 5$ \\
N233S & $1039 \pm 26$ & $7.5 \pm 0.2$ & $2302 \pm 112$ & $1370 \pm 74$ & $184 \pm 3$ \\
TeEgl5A & $732 \pm 10$ & $7.4 \pm 0.3$ & $1014 \pm 54$ & $600 \pm 24$ & $81.1 \pm 7.5$ \\
TeEgl5A_G216A & $523 \pm 30$ & $10.9 \pm 0.4$ & $1255 \pm 94$ & $732 \pm 43$ & $61.2 \pm 6.7$ \\
TeEgl5A_G216N & $368 \pm 15$ & $11.3 \pm 0.6$ & $958 \pm 76$ & $559 \pm 33$ & $49.4 \pm 4.3$ \\
PoCel5 & $401 \pm 3$ & $5.6 \pm 0.3$ & $534 \pm 28$ & $311 \pm 37$ & $55.1 \pm 5.2$ \\
PoCel5_G210A & $374 \pm 2$ & $5.5 \pm 0.4$ & $599 \pm 36$ & $337 \pm 43$ & $62.5 \pm 12.1$ \\
PoCel5_G210N & $166 \pm 4$ & $6.9 \pm 0.6$ & $280 \pm 32$ & $163 \pm 24$ & $23.7 \pm 3.2$ \\
\hline
\end{tabular}


Table 2 The substrate specificities of GtCel5 and its variants

\begin{tabular}{lll}
\hline Enzymes & CMC-Na (U/mg) & $\begin{array}{l}\text { Barley } \beta \text {-glucan } \\
(\mathbf{U} / \mathbf{m g})\end{array}$ \\
\hline GtCel5 & $1117 \pm 43$ & $6257 \pm 26$ \\
N233G & $1901 \pm 21$ & $8383 \pm 57$ \\
N233A & $1419 \pm 22$ & $7866 \pm 56$ \\
N233D & $1185 \pm 35$ & $5869 \pm 33$ \\
N233S & $1039 \pm 26$ & $5474 \pm 43$ \\
\hline
\end{tabular}

effect on the $\mathrm{pH}$-activity and temperature-activity profiles of TeEgl5A and PoCel5. However, great changes were detected on the catalytic performance of variants, as the specific activities of TeEgl5A_G216N and PoCel5_G210N decreased to 50 and $41 \%$ of the wild types (Table 1 ). The kinetic values of the variants showed similar trends, i.e., decreased or similar substrate affinity and catalytic efficiencies. The results suggested that glycine at position 233 on loop 6 does make a contribution to the catalytic performance of GH5 cellulases.

\section{Homology modeling and MD simulation}

To determine the structural changes caused by mutation at position 233, the modeled structures of GtCel5 and its variants N233A, N233D, and N233G with and without substrate (G4) were constructed. MD simulations of $20 \mathrm{~ns}$ at $323 \mathrm{~K}$ were then performed. The RMSD of $\mathrm{C}_{\alpha}$ atoms tended to be at equilibrium after $5 \mathrm{~ns}$, and thus, the simulation trajectory of the last 5 ns was selected for further analysis. As shown in Fig. 4a, the RMSD values of variants N233A and N233G were lower than that of GtCel5, suggesting that variants have more stable conformations than the wild type. Moreover, the average RMSF values of N233A (1.84 $\AA$ ) and N233G (1.87 $\AA$ ) at loop 6 were higher than that of GtCel5 (1.74 $\AA$ ) and N233D (1.46 $\AA$ ) (Fig. 4b). These results suggested that loop 6, containing the position 233 is more flexible in variants $\mathrm{N} 233 \mathrm{~A}$ and N233G than in the GtCel5 and mutant N233D, which may affect the interaction between enzyme and substrate.

The conformations of GtCel5 and its variants in the force field AMBER99SB were chosen for the analysis of putative hydrogen bonds. As shown in Fig. 5 and Table 3, the Asn233 of GtCel5 and the Asp233 of N233D formed two hydrogen bonds with Tyr228 and Asp230, and the Tyr228 formed one more hydrogen bond with the catalytic residue Glu267. These three hydrogen bonds had the occupancy rates of 20-40\%. However, in variants N233A and N233G, Ala233, and Gly233 form only one hydrogen bond with Asp230; the occupancy rates were 35 and 53\%, respectively; and the hydrogen bond between Tyr228 and Glu267 was absent. The results confirmed that mutation at position 233 has significant effects on the local hydrogen-bonding network.

\section{Interactions between residue $\mathbf{2 3 3}$ and the substrate}

The interactions between residue 233 and the substrate were analyzed using the YASARA software. As shown in Fig. 6, one hydrogen bond was formed between the A233@O and G4@H6O in variant N233A-cellotetraose complex or G233@O and G4@H6O in N233G-cellotetraose complex. The occupancy rates of these hydrogen bonds were up to 37 and 45\%, respectively. However, this hydrogen bond was absent in the GtCel5. These results are in accordance with the increased catalytic efficiencies of the two variants. Based on the MM/PBSA calculations, the wild-type $G t C e l 5$ has a binding free energy $(\Delta G)$ of $-2.7 \pm 0.2 \mathrm{k}_{\mathrm{cal}} / \mathrm{mol}$, while variants $\mathrm{N} 233 \mathrm{~A}$ and $\mathrm{N} 233 \mathrm{G}$ exhibit much lower $\Delta G$ values $(-22.2 \pm 0.2$ and
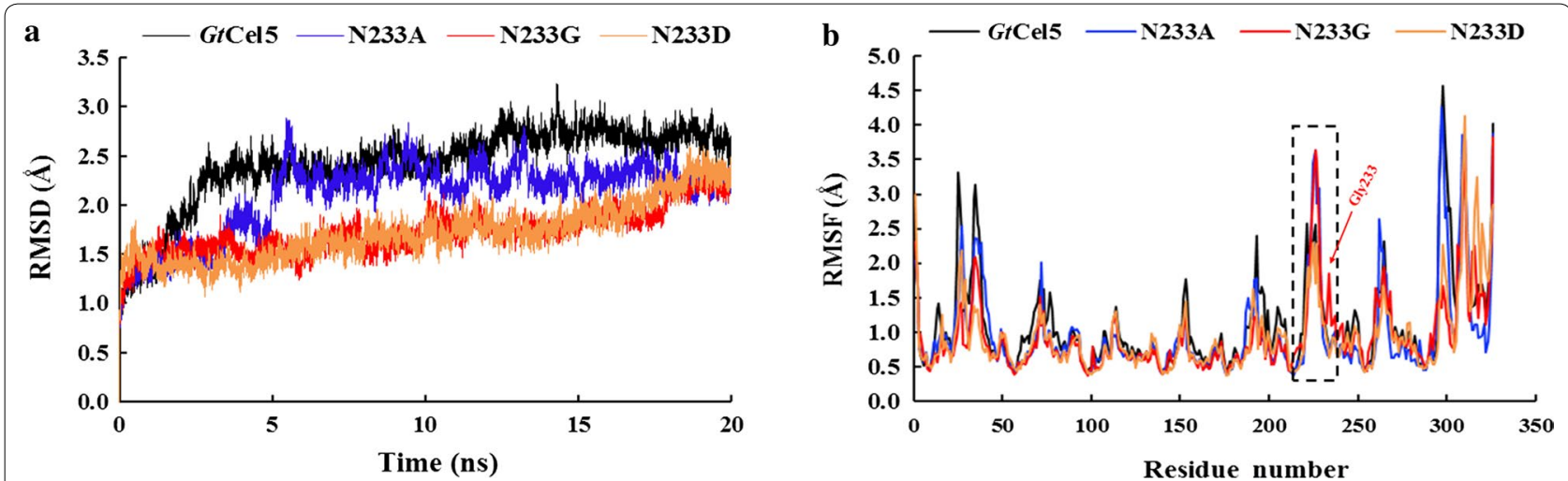

Fig. 4 MD simulation analysis of the wild-type GtCel5 and its variants, N233A, N233D, and N233G, using the force field of AMBER99SB. The data are collected at $323 \mathrm{~K}$ for a minimum of $20 \mathrm{~ns}$. a The RMSD values. The trajectories of first $5 \mathrm{~ns}$ were treated as equilibration periods, and the trajectories of the last 15 ns were used for data analyses. $\mathbf{b}$ The RMSF values. The loop 6 region is indicated by the dashed box 


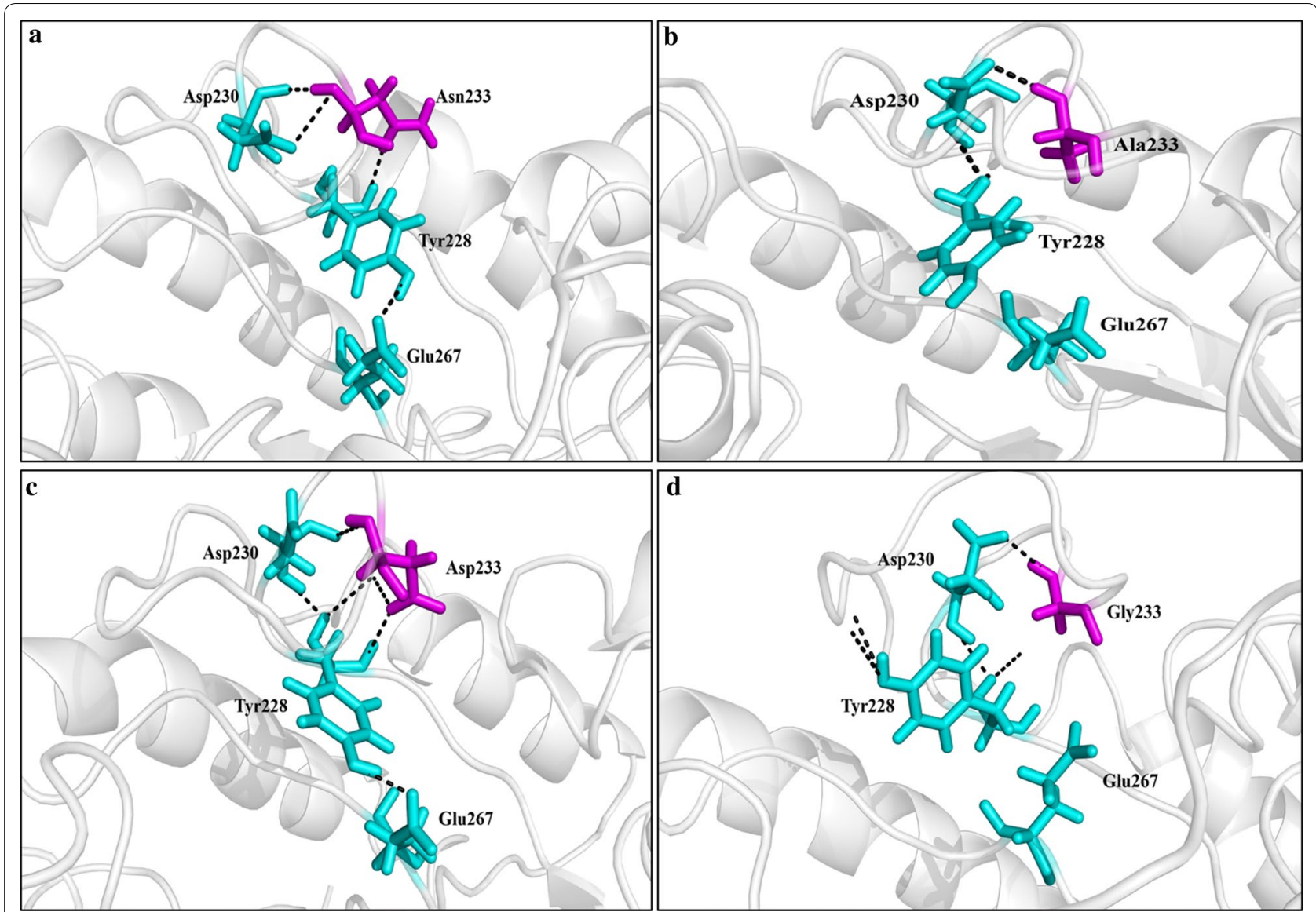

Fig. 5 Hydrogen bonds probably formed at position 233 within GtCel5 and its variants without substrate. The residue of position 233 is shown in purple. a GtCel5. b N233A. c N233D. d N233G

- 32.4 $\mathrm{k}_{\mathrm{cal}} / \mathrm{mol}$, respectively). Moreover, the binding energies of GtCel5 and its variants at position 233 were also calculated. As shown in Fig. 7, N233G showed lower binding energy than that of N233A and GtCel5. These findings revealed a stronger interaction between the substrate and N233G.

\section{Discussion}

GH5 is a large GH family containing enzymes with broad substrate specificity and various activities, and those from fungi are generally acidic and mesophilic [4]. In this study, an acidic, mesophilic GH5 cellulase was identified in G. trabeum CBS 900.73. Based on the key amino acid residue at position 233 of loop 6, the 51 fungal cellulases of GH5 were classified into two main groups: one with asparagine as shown in GtCel5 and 3QR3 [7], and the other with glycine, as in cellulases TeEgl5A, PoCel5 and 1GZJ [6]. The roles of the residue at position 233 were then revealed in $G t$ Cel 5 by saturation mutagenesis, which were further verified by reverse mutation in GtCel5 homologs TeEgl5A and PoCel5.
Mobile surface loops have been found to play key roles in protein functions. For example, the thermostability and activity of cellobiohydrolase $\mathrm{TeCel7A}$ were improved by introducing more disulfide bridges to the loop structures [34]. As for the $N$ - $\alpha$-acetyl transferase from Sulfolobus solfataricus, changing the residues of the loop region between sheets $\beta_{3}$ and $\beta_{4}$ destroyed the hydrogen bond network and caused a decrease of $3-7{ }^{\circ} \mathrm{C}$ in the protein melting temperature [35]. In the present study, the residue at position 233 was found to have effects on both thermal adaptation and catalytic efficiency of GtCel5. The temperature-activity profiles of $\mathrm{GtCel} 5$ and its variants showed great variations. Bioinformatic analysis indicated that the local hydrogen bond network of loop 6 (Fig. 5) varied in the enzymes, which probably contribute to the thermal adaptability.

As the best variants, the catalytic performances of N233A and N233G were compared to that of commercial cellulases. When using CMC-Na as the substrate, the specific activities of the widely used cellulase Cel5A from Hypocrea jecorina (Trichoderma reesei) [36] and 


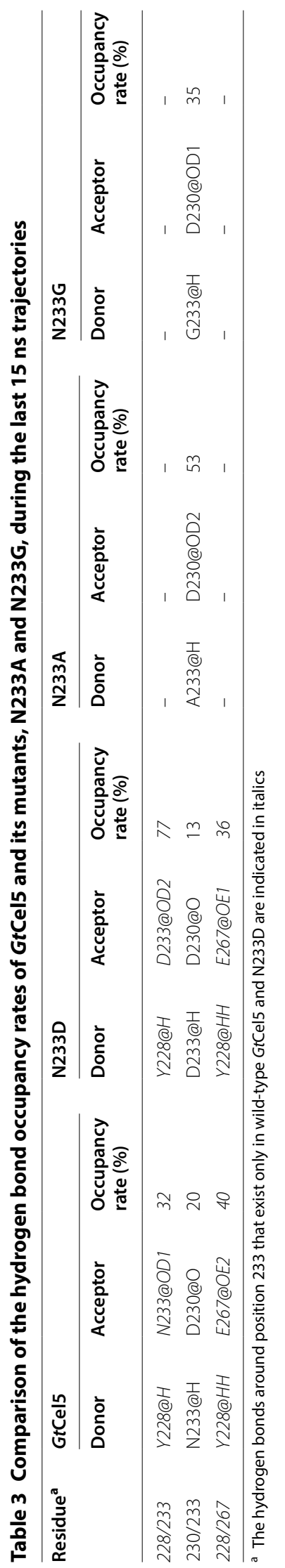




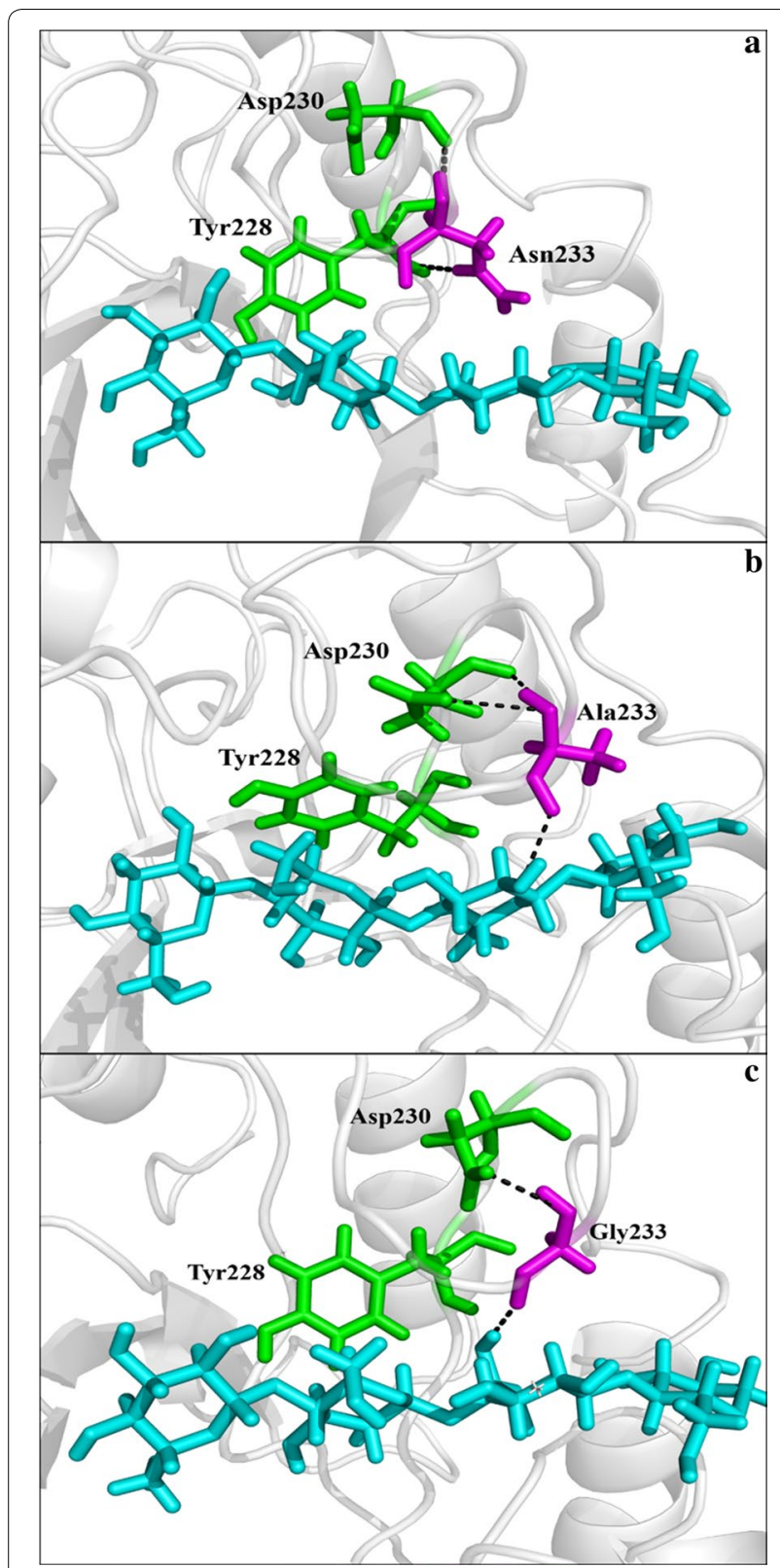

Fig. 6 Hydrogen bonds probably formed at position 233 within the complexes of GtCel5 or its variants and cellotetraose. The residue of position 233 is shown in purple, and the cellotetraose is shown in blue. a GtCel5. b N233A. c N233G

the commercial cellulase from Thermotoga maritime (Magazyme) are 215.6 and $245 \mathrm{U} / \mathrm{mg}$, respectively, which were much lower than those of N233A (1419 U/mg) and N233G (1901 U/mg). However, other variants had similar or decreased activities (Fig. 3). MD simulation analyses indicated that variants N233G and N233A have higher RMSF values in the region of loop 6, which are correspondent to the improved loop flexibility, especially in N233G. Glycine without side chain has been found to contribute to conformational flexibility of some loop regions, and consequently has effects on enzymatic catalysis and substrate binding. For example, a glycine-rich loop is postulated to undergo conformational change for substrate binding in the mitochondrial-processing peptidase [36], while residue G76 contributes to the activesite loop flexibility of a pepsin [37]. Variants N233A and N233G with more flexible loop 6 showed improvements in substrate affinity (decreased $K_{\mathrm{m}}$ values), turnover rate (increased $k_{\text {cat }}$ values), and catalytic efficiency (increased $k_{\text {cat }} / K_{\mathrm{m}}$ values) (Table 1$)$, which confirmed the effects of alanine and glycine on the loop conformation. Moreover, MD calculation indicated that the improved flexibility of the loop 6 probably affects the hydrogen-bonding network near the active site indirectly (Fig. 5, Table 3). As a result, the conformational freedom of catalytic Glu267 is reduced. However, without the steric hindrance caused by the hydrogen bond between Tyr228 and Glu267, variants N233A and N233G probably experienced a conformational change of the catalytic pocket. Consequently, these variants having higher mobility at loop 6 and a different hydrogen bond pattern at the active site may bind substrates more easily and thus catalyze the hydrolysis of substrate more efficiently.

To the best of our knowledge, hydrogen bonds are also crucial in substrate recognition and binding [38, 39]. Therefore, we also investigated the hydrogen bonds between the enzyme and substrate. MD analysis of the enzyme-substrate complex dynamics indicated that the Asn 233 of GtCel5 has no direct ligand contact with G4, while Ala233 or Gly233 of variants N233A and N233G was more likely to form a hydrogen bond with G4 with higher occupancy rates. Although this hydrogen bond was also identified in N233D, the occupancy rate was much lower (27\%). This result is in agreement with the increased catalytic efficiencies of variants N233A and N233G. Similar results have been reported in the $\operatorname{TrCel7A}$ from T. reesei, in which hydrogen bond interaction exists in the whole catalytic process and plays a role of special importance in stabilizing the intermediate state and improvement of the catalytic performance [40]. Besides, in TlXyn10A_P from Talaromyces leycettanus, G149D on the loop 4 is able to form a hydrogen bond with substrate and probably plays a major role in the improvement of catalytic performance [41]. To analyze the binding affinity of substrate and enzyme, we performed MM/PBSA calculations, and found that the binding energies of GtCel5 and its variants are in the order of N233G $<\mathrm{N} 233 \mathrm{~A}<\mathrm{GtCel} 5$. These data are correspondent to the experimental work that showed N233G and N233A having higher affinity with cellotetraose than withGtCel5 (Tables 1,2). Therefore, the substitution of 


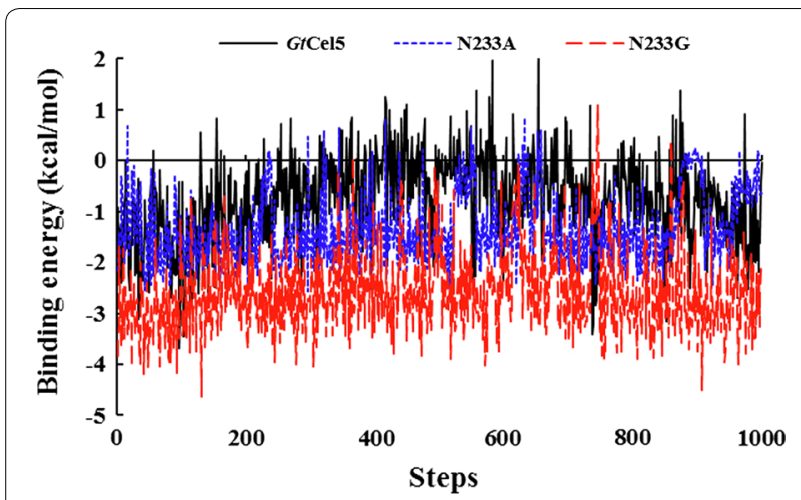

Fig. 7 Binding energies of the residue at position 233 within GtCel5, $\mathrm{N} 233 \mathrm{~A}$, and N233G in the last 1000 steps of MD trajectories

Asn233 with alanine or glycine might cause the enzyme to form more stable hydrogen bonds with the substrate and improve the interactions between enzyme and substrate, and consequently enhance the substrate's binding and catalytic efficiencies.

\section{Conclusions}

In the present study, an acidic, mesophilic cellulase of GH5 was identified in G. trabeum CBS 900.73 and produced in P. pastoris GS115. Structure and sequence analyses indicated that the residue at position 233 on loop 6 plays a crucial role in the catalytic performance of GH5 cellulases. By increasing the local hydrogen bond interactions around the residue at position 233 and between the enzyme and substrate, the substrate affinity was enhanced, as was the catalytic efficiency. Considering the significance of GH5 cellulases in biomass conversion, the findings are valuable for the protein engineering of GH5 cellulases in the viewpoints of research, development, and industrial applications.

\section{Additional files}

\section{Additional file 1: Table S1. Primers used in this study}

Additional file 2: Fig. S1. The phylogenetic analysis of GtCel5 and other GH5 enzymes of bacterial and fungal sources. GenBank accession numbers or PDB numbers are shown. Fig. S2. SDS-PAGE analysis of GtCel5 and its variants. $M$, the molecular weight markers; $1,4,7$ and 10 , the crude enzymes; 2, 5, 8 and 11, the purified enzymes; 3, 6, 9 and 12, the deglycosylated enzymes with Endo $\mathrm{H}$ treatment. Fig. S3. SDS-PAGE analysis of TeEgI5A, PoCel5 and their variants. $\mathrm{M}$, the molecular weight markers; 1,4 and 7, the crude enzymes; 2,5 and 8, the purified enzymes; 3,6 and 9, the deglycosylated enzymes with Endo $\mathrm{H}$ treatment. Fig. $\mathbf{S 4 .}$ Enzymatic properties of the wild type TeEgl5A, PoCel5 and their variants. (A) pH-activity profiles of TeEgl5A and its variants tested at the optimal temperature of each enzyme $\left(90^{\circ} \mathrm{C}\right)$ over the $\mathrm{pH}$ range of $3.0-7.0$ for $10 \mathrm{~min}$. (B) Temperature-activity profiles of TeEgl5A and its variants tested at the optimal $\mathrm{pH}$ of each enzyme in the temperature range of $50-95^{\circ} \mathrm{C}$ for $10 \mathrm{~min}$. (C) pH-activity profiles of PoCel5 and its variants tested at the optimal temperature $\left(60^{\circ} \mathrm{C}\right)$ over the $\mathrm{pH}$ range of $3.0-8.0$ for $10 \mathrm{~min}$. (D) Temperature-activity profiles of PoCel5 and its variants tested at the optimal pH of each enzyme in the temperature range of $40-90^{\circ} \mathrm{C}$ for $10 \mathrm{~min}$.

\section{Abbreviations}

CMC-Na: carboxymethycellulose sodium; G4: cellotetraose; MD: molecular dynamics; RMSD: root-mean-square deviation; RMSF: root-mean-square fluctuation; MM/PBSA: molecular mechanics/Poisson Boltzmann and surface area continuum solvation.

\section{Authors' contributions}

FZ performed the experiments and wrote the manuscript. TT and XW participated in the bioinformatic analysis. YW, XS, XX, and RM analyzed the data and revised the manuscript. BY and $\mathrm{HL}$ conceived and designed the experiments and revised the manuscript. All the authors read and approved the final manuscript.

\section{Author details}

${ }_{1}^{1}$ Key Laboratory for Feed Biotechnology of the Ministry of Agriculture, Feed Research Institute, Chinese Academy of Agricultural Sciences, No. 12 South Zhongguancun Street, Haidian, Beijing 100081, People's Republic of China. ${ }^{2}$ College of Biological Sciences and Biotechnology, Beijing Forestry University, Beijing 100083, People's Republic of China.

\section{Acknowledgements \\ Not applicable.}

\section{Competing interests}

The authors declare that they have no competing interests.

\section{Ethics approval and consent to participate}

Not applicable.

\section{Availability of data and materials}

The dataset supporting the conclusions of this article are included within the article and its Additional files 1 and 2.

\section{Funding}

This work was supported by the National Natural Science Foundation of China (No. 31572446), the National High-Tech Research and Development Program of China (863 Program, No. 2013AA102803), the National Chicken Industry Technology System of China (No. CARS-42), and the National Key Research and Development Program of China (No. 2016YFD0501409).

\section{Publisher's Note}

Springer Nature remains neutral with regard to jurisdictional claims in published maps and institutional affiliations.

Received: 11 July 2017 Accepted: 14 March 2018

Published online: 22 March 2018

\section{References}

1. Jönsson LJ, Alriksson B, Nilvebrant NO. Bioconversion of lignocellulose: inhibitors and detoxification. Biotechnol Biofuels. 2013;6:16.

2. Hoshino E, Shiroishi M, Amano Y, Nomura M, Kanda T. Synergistic actions of exo-type cellulases in the hydrolysis of cellulose with different crystallinities. J Ferment Bioeng. 1997;84:300-6.

3. Lombard V, Golaconda Ramulu H, Drula E, Coutinho PM, Henrissat B. The carbohydrate-active enzymes database (CAZy) in 2013. Nucleic Acids Res. 2014;42:D490-5.

4. Aspeborg H, Coutinho PM, Wang Y, Brumer H, Henrissat B. Evolution, substrate specificity and subfamily classification of glycoside hydrolase family 5 (GH5). BMC Evol Biol. 2013;12:186.

5. Tseng CW, Ko TP, Guo RT, Huang JW, Wang HC, Huang CH, Cheng YS, Wang AH, Liu JR. Substrate binding of a GH5 endoglucanase from the ruminal fungus Piromyces rhizinflata. Acta Crystallogr Sect F. 2011;67:1189-94.

6. Lo Leggio L, Larsen S. The $1.62 \AA$ structure of Thermoascus aurantiacus endoglucanase: completing the structural picture of subfamilies in glycoside hydrolase family 5. FEBS Lett. 2002;523:103-8.

7. Lee TM, Farrow MF, Arnold FH, Mayo SL. A structural study of Hypocrea jecorina Cel5A. Protein Sci. 2011;20:1935-40. 
8. Liu G, Li Q, Shang N, Huang JW, Ko TP, Liu W, Zheng Y, Han X, Chen $Y$, Chen CC, Jin J, Guo RT. Functional and structural analyses of a 1,4- $\beta$-endoglucanase from Ganoderma lucidum. Enzyme Microb Technol. 2016;86:67-74.

9. Yan J, Liu W, Li Y, Lai HL, Zheng Y, Huang JW, Chen CC, Chen Y, Jin J, Li H, Zhong LH, Guo RT. Functional and structural analysis of Pichia pastorisexpressed Aspergillus niger 1,4- $\beta$-endoglucanase. Biochem Biophys Res Commun. 2016;475:8-12.

10. Wierenga R. The TIM-barrel fold: a versatile framework for efficient enzymes. FEBS Lett. 2001;492:193-8.

11. Tu T, Pan X, Meng K, Luo H, Ma R, Wang Y, Yao B. Substitution of a non-active-site residue located on the T3 loop increased the catalytic efficiency of endo-polygalacturonases. Process Biochem. 2016;51:1230-8.

12. Zou J, Kleywegt GJ, Ståhlberg J, Driguez H, Nerinckx W, Claeyssens M, Koivula A, Teeri TT, Jones TA. Crystallographic evidence for substrate ring distortion and protein conformational changes during catalysis in cellobiohydrolase Ce16A from Trichoderma reesei. Structure. 1999;7:1035-45.

13. Varrot A, Schülein M, Davies GJ. Structural changes of the active site tunnel of Humicola insolens cellobiohydrolase, Cel6A, upon oligosaccharide binding. Biochemistry. 1999:38:8884-91.

14. Meinke A, Damude HG, Tomme P, Kwan E, Kilburn DG, Miller RCJ, Warren RA, Gilkes NR. Enhancement of the endo- $\beta$-1,4-glucanase activity of an exocellobiohydrolase by deletion of a surface loop. J Biol Chem. 1995;270:4383-6.

15. Cheng YS, Ko TP, Huang JW, Wu TH, Lin CY, Luo W, Li Q, Ma Y, Huang CH, Wang AH, Liu JR, Guo RT. Enhanced activity of Thermotoga maritima cellulase 12A by mutating a unique surface loop. Appl Microbiol Biotechnol. 2012;95:661-9.

16. Badieyan S, Bevan DR, Zhang C. A salt-bridge controlled by ligand binding modulates the hydrolysis reaction in a $\mathrm{GH} 5$ endoglucanase. Protein Eng Des Sel. 2012;25:223-33.

17. Yuan SF, Wu TH, Lee HL, Hsieh HY, Lin WL, Yang B, Chang CK, Li Q, Gao J, Huang $\mathrm{CH}$. Biochemical characterization and structural analysis of a bifunctional cellulase/xylanase from Clostridium thermocellum. J Biol Chem. 2015;290:5739-48.

18. Bommarius AS, Broering JM, Chaparro-Riggers JF, Polizzi KM. Highthroughput screening for enhanced protein stability. Curr Opin Biotechnol. 2006;17:606-10.

19. Liang C, Fioroni M, Rodríguez-Ropero F, Xue Y, Schwaneberg U, Ma Y Directed evolution of a thermophilic endoglucanase (Cel5A) into highly active Cel5A variants with an expanded temperature profile. J Biotechnol. 2011:154:46-53

20. Wang K, Luo H, Bai Y, Shi P, Huang H, Xue X, Yao B. A thermophilic endo-1,4- $\beta$-glucanase from Talaromyces emersonii CBS394.64 with broad substrate specificity and great application potentials. Appl Microbiol Biotechnol. 2014;98:7051-60.

21. Tamura K, Dudley J, Nei M, Kumar S. MEGA4: molecular evolutionary genetics analysis (MEGA) software version 4.0. Mol Biol Evol. 2007;24:1596-9.

22. Pearson WR. Searching protein sequence libraries: comparison of the sensitivity and selectivity of the Smith-Waterman and FASTA algorithms. Genomics. 1991;11:635-50.

23. Thompson JD, Higgins DG, Gibson TJ. CLUSTAL W: improving the sensitivity of progressive multiple sequence alignment through sequence weighting, positions-specific gap penalties and weight matrix choice. Nucleic Acids Res. 1994;22:4673-80.

24. Miller GL. Use of dinitrosalicylic acid reagent for determination of reducing sugar. Anal Chem (Wash). 1959;31:426-8.

25. Lindorff-larsen K, Piana S, Palmo K, Maragakis P, Klepeis JL, Dror RO, Shaw DE. Improved side-chain torsion potentials for the Amber ff99SB protein force field. Proteins. 2010;78:1950-8.
26. Hornak V, Abel R, Okur A, Strockbine B, Roitberg A, Simmerling C. Comparison of multiple Amber force fields and development of improved protein backbone parameters. Proteins. 2006;65:712-25.

27. Jorgensen WL, Chandrasekhar J, Madura JD, Impey RW, Klein ML. Comparison of simple potential functions for simulating liquid water. J Chem Phys. 1983;79:926-35

28. Case DA, Darden TA, Simmerling CL, Wang J, Duke RE, Luo R, Walker RC, Zhang W, Merz KM, Roberts B, Wang B, Hayik S, Roitberg A, Seabra G, Kolossvai I, Wong KF, Paesani F, Vanicek J, Liu J, Wu X, Brozell SR, Steinbrecher T, Gohlke H, Cai Q, Ye X, Wang J, Hsieh M-J, Cui G, Roe DR, Mathews DH, Seetin MG, Sagui C, Babin V, Luchko T, Gusarov S, Kovalenko A, Kollman PA. AMBER 11. San Francisco: University of California; 2010.

29. Kirschner KN, Yongye AB, Tschampel SM, González-Outeiriño J, Daniels CR, Foley BL, Woods RJ. GLYCAM06: a generalizable biomolecular force field. Carbohydrates. J Comput Chem. 2008;29:622-55.

30. Kollman PA, Massova I, Reyes C, Kuhn B, Huo S, Chong L, Lee M, Lee T, Duan Y, Wang W, Donini O, Cieplak P, Srinivasan J, Case DA, Cheatham TR. Calculating structures and free energies of complex molecules: combining molecular mechanics and continuum models. Acc Chem Res. 2001:32:889-97.

31. Steiner T. The hydrogen bond in the solid state. Angew Chem Int Ed. 2002:41:48-76.

32. Zhai X, Amyes TL, Richard JP. The role of loop-clamping side chains in catalysis by triosephosphate isomerase. J Am Chem Soc. 2015:137:15185-97.

33. Zhai $X$, Go MK, O'Donoghue AC, Amyes TL, Pegan SD, Wang Y, Loria JP, Mesecar AD, Richard JP. Enzyme architecture: the effect of replacement and deletion mutations of loop 6 on catalysis by triosephosphate isomerase. Biochemistry. 2014;53:3486-501.

34. Voutilainen SP, Murray PG, Tuohy MG, Koivula A. Expression of Talaromyces emersonii cellobiohydrolase Cel7A in Saccharomyces cerevisiae and rational mutagenesis to improve its thermostability and activity. Protein Eng Sel. 2010:23:69-79.

35. Chang YY, Hsu CH. Multiple conformations of the loop region confers heat-resistance of SsArd1, a thermophilic NatA. ChemBioChem. 2015:17:214-7

36. Nagao Y, Kitada S, Kojima K, Toh H, Kuhara S, Ogishima T, Ito A. Glycinerich region of mitochondrial processing peptidase alpha-subunit is essential for binding and cleavage of the precursor proteins. J Biol Chem. 2000;275:34552-6.

37. Okoniewska M, Tanaka T, Yada RY. The pepsin residue glycine-76 contributes to active-site loop flexibility and participates in catalysis. Biochem J. 2000;349:169

38. Kim D, Bo HP, Jung BW, Kim M, Hong SI, Lee DS. Identification and molecular modeling of a family 5 endocellulase from Thermus caldophilus GK24, a cellulolytic strain of Thermus thermophilus. Int J Mol Sci. 2006;7:571-89.

39. Verdoucq L, Morinière J, Bevan DR, Esen A, Vasella A, Henrissat B, Czzze M. Structural determinants of substrate specificity in family $1 \beta$-glucosidases: novel insights from the crystal structure of sorghum dhurrinase-1, a plant $\beta$-glucosidase with strict specificity, in complex with its natural substrate. J Biol Chem. 2004:279:31796-803.

40. Li J, Du L, Wang L. Glycosidic-bond hydrolysis mechanism catalyzed by cellulase Cel7A from Trichoderma reesei: a comprehensive theoretical study by performing MD, QM and QM/MM calculations. J Phys Chem B. 2010;114:15261-8.

41. Wang X, Huang H, Xie X, Ma R, Bai Y, Zheng F, You S, Zhang B, Xie H, Yao B. Improvement of the catalytic performance of a hyperthermostable GH10 xylanase from Talaromyces leycettanus JCM12802. Bioresour Technol. 2016;222:277-84 